\title{
CONSERVAÇÃO DE PRODUTO MINIMAMENTE PROCESSADO DE GOIABAS 'KUMAGAI' E 'PEDRO SATO'
}

\author{
SARAH MARIA ATHIÊ DE SOUZA ${ }^{2}$, FLAVIA CRISTINA CAVALINI ${ }^{3}$, \\ ANGELO PEDRO JACOMINO ${ }^{4}$, EDWIN MOISÉS MARCOS ORTEGA ${ }^{5}$
}

RESUMO - O processamento mínimo permite a obtenção de produtos com qualidade, frescor e conveniência para o consumidor. O objetivo deste trabalho foi determinar os efeitos de tipos de corte e de temperaturas de armazenamento na conservação de produto minimamente processado de goiabas 'Kumagai' e 'Pedro Sato', associando-se goiabas de polpa branca e de polpa vermelha num único produto, como forma de torná-lo mais atraente e nutritivo. Os frutos foram minimamente processados em rodelas e fatias, acondicionados em bandejas de poliestireno expandido, recobertas com filme de PVC $17 \mu \mathrm{m}$ e armazenadas a $5^{\circ} \mathrm{C}$ e $15^{\circ} \mathrm{C}$, durante 9 dias. As análises foram realizadas a cada 3 dias quanto às suas características físicas e químicas (firmeza do mesocarpo e da região placentária, cor da casca e da região placentária e teores de sólidos solúveis, acidez titulável e ácido ascórbico) e sensoriais (aparência). As temperaturas e os tipos de cortes não influenciaram nos conteúdos de ácido ascórbico, sólidos solúveis e acidez titulável. O corte tipo rodela manteve por mais tempo a firmeza do mesocarpo e da região placentária. A temperatura de $5^{\circ} \mathrm{C}$ preservou a cor da casca, enquanto a de $15^{\circ} \mathrm{C}$ e o corte tipo fatia implicaram maior escurecimento da polpa na região placentária. $\mathrm{O}$ produto minimamente processado mantido a $5^{\circ} \mathrm{C}$, bem como o corte em rodelas foram os preferidos pelos provadores.

Termos para indexação: Psidium guajava, qualidade, vida de prateleira.

\section{CONSERVATION OF 'KUMAGAI' AND 'PEDRO SATO' GUAVAS MINIMALLY PROCESSED}

\begin{abstract}
The minimal processing allows obtaining products with high quality, freshness and great convenience to the consumer. In order to evaluate the use of white and red pulp guavas fruits together as a way to become more attractive and nutritional, the effect of types of cut and storage temperatures in guavas 'Kumagai' and 'Pedro Sato' minimally processed was evaluated. The fruits had been minimally processed in slice wheel and slices, packed in polystyrene trays, re-covered with PVC $17 \mu \mathrm{m}$ film and stored at 5 and $15^{\circ} \mathrm{C}$ during 9 days. The analyses had been carried out each 3 days to determine the physical-chemical characteristics (mesocarp and pulp firmness, skin and pulp color, soluble solids, titratable acidity, ascorbic acid) and the appearance. The temperature and types of cut did not influence the ascorbic acid, soluble solids and titratable acidity contents. Slice wheel had promoted the high firmness for mesocarp and pulp. The skin color was preserved at $5^{\circ} \mathrm{C}$, however the slice cut and at $15^{\circ} \mathrm{C}$ provided the browning of the fruits. The product minimally processed at $5^{\circ} \mathrm{C}$, as well as the cut in slice wheel, had been preferred by the tasters.
\end{abstract}

Index terms: Psidium guajava, quality, shelf life.

\section{INTRODUÇÃO}

O processamento mínimo é definido como qualquer alteração física causada em frutas ou hortaliças e mantém o estado fresco desses produtos (International Fresh-Cut Produce Association, 1999). Esta técnica oferece produtos com qualidade, frescor e conveniência, além de permitir a avaliação imediata da qualidade interna (Jacomino et al., 2004).
O processamento mínimo de frutas é uma das principais técnicas em ascensão no mercado, seguindo a tendência mundial do consumo de produtos in natura ou mais próximo possível destes. Por outro lado, as frutas minimamente processadas ainda são um desafio, devido à falta de conhecimento a respeito do comportamento fisiológico e bioquímico desses produtos. As operações envolvidas na preparação das mesmas, geralmente, são responsáveis

\footnotetext{
${ }^{1}$ (Trabalho 209-08). Recebido em: 11-08-2008. Aceito para publicação em: 13-01-2009. Parte do projeto de Iniciação Científica financiado pela FAPESP.

${ }^{2}$ Engenheira Agrônoma, email: sarah_athie@yahoo.com.br

${ }^{3}$ Engenheira Agrônoma, Doutoranda em Ciências, ESALQ/USP, Departamento de Ciências Biológicas, (19) 3429-4354, email: fccavali@yahoo.com.

${ }^{4}$ Professor Dr, ESALQ-USP, Departamento de Produção Vegetal, (19) 3429-4190, email: jacomino@esalq.usp.br ${ }^{5}$ Professor Dr, ESALQ-USP, Departamento de Ciências Exatas, (19) 3429-4145, email: edwin@esalq.usp.br.
} 
pela sua curta vida útil. O dano causado pelo corte ou descascamento é um dos maiores obstáculos na conservação dos produtos minimamente processados. Os tecidos fatiados, cuja superfície de exposição é maior, apresentam maiores taxas de respiração e, consequentemente, maiores alterações fisiológicas, bioquímicas e microbiológicas que o tecido inteiro (Porte \& Maia, 2001). De acordo com Brecht (1995), quanto maior a gravidade da injúria nos tecidos, maior é a velocidade de deterioração do produto minimamente processado. Assim, é de se esperar que diferentes espessuras de corte promovam respostas distintas quanto à qualidade e capacidade de conservação destes produtos.

As mudanças bioquímicas em frutos e vegetais minimamente processados são, em parte, consequência do efeito da temperatura na atividade enzimática. Em temperaturas superiores a $10^{\circ} \mathrm{C}$, a concentração de $\mathrm{CO}_{2}$ aumenta abruptamente devido à intensificação do metabolismo e proliferação microbiana (Varoquaux \& Wiley, 1994). O uso de baixa temperatura durante o preparo, conservação e comercialização destes produtos é fundamental para que eles alcancem a sua máxima vida de prateleira, sem perda de qualidade e sem riscos para a saúde do consumidor. Allong et al. (2000) verificaram que a temperatura de $5^{\circ} \mathrm{C}$ foi mais eficiente que $10^{\circ} \mathrm{C}$ em retardar o crescimento microbiano e preservar a qualidade sensorial de mangas minimamente processadas.

O Brasil é o segundo maior produtor mundial de goiaba, e as principais variedades produzidas são a 'Kumagai' (polpa branca) e a 'Paluma' (polpa vermelha). Embora ela seja uma fruta bastante conveniente, pois pode ser consumida com a casca e as sementes, Mattiuz et al. (2003) comprovaram a viabilidade do processamento mínimo de goiabas de polpa vermelha.

No presente trabalho, buscou-se associar uma variedade de polpa branca e uma de polpa vermelha num único produto, como forma de tornálo mais atraente. Neste caso, o aspecto nutricional também é valorizado, uma vez que a goiaba branca possui elevado teor de ácido ascórbico, enquanto a goiaba vermelha é rica em licopeno (Jacomino et al., 2007).

O objetivo deste trabalho foi determinar os efeitos de tipos de corte e de temperaturas de armazenamento na conservação de produto minimamente processado de goiabas 'Kumagai' e 'Pedro Sato'.

\section{MATERIAL E MÉTODOS}

Goiabas 'Kumagai' e 'Pedro Sato' foram colhidas em pomares comerciais nos municípios paulistas de Campinas e Vista Alegre do Alto, respectivamente, e transportadas ao Laboratório de PósColheita de Produtos Hortícolas do Departamento de Produção Vegetal da ESALQ/USP. Os frutos foram selecionados quanto ao estádio de maturação (cor da casca verde-clara, com início da cor amarela) utilizando-os no estádio 2, que é considerado adequado para o consumo (Azzolini et al., 2004; Cavalini, 2004), ausência de danos mecânicos e tamanho de aproximadamente $250 \mathrm{~g}$.

Os frutos foram lavados com detergente neutro, imersos em solução de hipoclorito de sódio a $200 \mathrm{mg}$. $\mathrm{L}^{-1}$, por 10 minutos, armazenados a $10^{\circ} \mathrm{C}$, durante 12 horas, e submetidos ao processamento em ambiente a $12^{\circ} \mathrm{C}$, sob condições higiênicas, ou seja, os operadores utilizaram botas, aventais, luvas, máscaras e toucas, como parte das condições mínimas de assepsia.

As goiabas foram minimamente processadas em rodelas e fatias e acondicionadas em bandejas contendo $50 \%$ da variedade Kumagai e $50 \%$ da variedade Pedro Sato, de maneira que os pedaços foram dispostos realçando a combinação de cores das variedades. Os tratamentos ficaram assim constituídos: a) misto de 'Kumagai' e 'Pedro Sato' em fatias, armazenado a $5^{\circ} \mathrm{C}$; b) misto de 'Kumagai' e 'Pedro Sato' em fatias, armazenado a $15^{\circ} \mathrm{C}$; c) misto de 'Kumagai' e 'Pedro Sato' em rodelas, armazenado a $5^{\circ} \mathrm{C}$, e d) misto de 'Kumagai' e 'Pedro Sato' em rodelas, armazenado a $15^{\circ} \mathrm{C}$.

Para a obtenção das rodelas, os frutos foram cortados transversalmente na espessura de aproximadamente $1,0 \mathrm{~cm}$. As fatias foram obtidas cortando-se o fruto longitudinalmente ao meio, o que resultou em 2 partes iguais, as quais foram subdivididas longitudinalmente até totalizar 8 fatias por fruto, com dimensões semelhantes entre si. Em ambos os cortes, eliminou-se aproximadamente $0,5 \mathrm{~cm}$ das extremidades apical e peduncular do fruto.

Porções de aproximadamente 220 gramas de goiabas 'Kumagai' e 'Pedro Sato' foram acondicionadas nas bandejas de poliestireno expandido, recobertas com filme de PVC $17 \mu \mathrm{m}$ e armazenadas durante 9 dias.

Avaliaram-se, a cada 3 dias, a firmeza da região placentária e do mesocarpo, a cor da região placentária e da casca, a aparência e os teores de sólidos solúveis, acidez titulável e ácido ascórbico. Para as determinações dos teores de sólidos solúveis, acidez tituláveis e ácido ascórbico, utilizou-se polpa 
homogeneizada do misto de goiabas 'Kumagai' e 'Pedro Sato'. As demais análises foram realizadas separadamente para cada variedade.

A cor foi determinada com colorímetro Minolta, modelo CR-300. Foram feitas 8 leituras, sendo 4 de 'Kumagai' e 4 de 'Pedro Sato' por repetição, tanto em fatias como em rodelas distintas. Os resultados foram expressos em ângulo de cor $\left(\mathrm{h}^{\circ}\right)$ para a casca e luminosidade $\left(\mathrm{L}^{*}\right)$ para a região placentária.

A firmeza foi determinada com penetrômetro digital, ponteira de $6 \mathrm{~mm}$, tomando-se 8 leituras, sendo 4 de 'Kumagai' e 4 de 'Pedro Sato' por repetição, em fatias ou rodelas distintas. A firmeza da casca foi determinada no mesocarpo, e a da polpa, na região placentária. Os resultados foram expressos em Newton (N).

O teor de sólidos solúveis (SS) foi determinado por leitura direta em refratômetro digital Atago modelo Palete 101, utilizando-se de polpa homogeneizada em triturador doméstico tipo 'mixer'. Os resultados foram expressos em ${ }^{\circ}$ Brix.

A acidez titulável (AT) foi determinada de acordo com metodologia descrita pela AOAC (1997), onde $10 \mathrm{~g}$ de polpa foram homogeneizadas em $90 \mathrm{~mL}$ de água destilada. A solução foi titulada com $\mathrm{NaOH}$ a $0,1 \mathrm{~mol} \mathrm{~L}^{-1}$, até $\mathrm{pH} 8,1$. Os resultados foram expressos em $\%$ de ácido cítrico.

O teor de ácido ascórbico foi determinado por titulometria, de acordo com metodologia descrita pela AOAC (1997), e os resultados, expressos em mg de ácido ascórbico por $100 \mathrm{~g}$ de polpa.

$\mathrm{O}$ delineamento foi o inteiramente casualizado, em esquema fatorial 2x2 (2 tipos de corte e 2 temperaturas), com 4 repetições, de uma bandeja, em cada dia de análise. Os resultados foram submetidos à análise de variância e teste de Tukey para comparação de médias, a $5 \%$ de probabilidade.

A avaliação sensorial (aparência) foi realizada por uma equipe de 30 provadores não treinados, utilizando-se de escala de notas adaptadas de Peryam \& Girardot (1952), onde: 5=ótimo; 4=bom; 3=regular; $2=$ ruim, e $1=$ péssimo. A nota 3 foi considerada como limite de aceitabilidade. $\mathrm{O}$ delineamento estatístico foi de blocos ao acaso, sendo cada provador considerado um bloco. Os resultados foram submetidos à análise de variância e teste de Tukey para comparação de médias, a $5 \%$ de probabilidade.

\section{RESULTADOS E DISCUSSÃO}

Os produtos minimamente processados de goiabas, armazenados a $5^{\circ} \mathrm{C}$, foram analisados até o $9^{\circ}$ dia, e aqueles armazenados a $15^{\circ} \mathrm{C}$, apenas até o $6^{\circ}$ dia, devido ao visível desenvolvimento de microrganismos.

As goiabas 'Kumagai' e 'Pedro Sato' minimamente processadas perderam firmeza ao longo do armazenamento; no entanto, não houve influência da temperatura nesta variável. Os valores iniciais da firmeza do mesocarpo foram de aproximadamente $40 \mathrm{~N}$, e os valores finais, em torno de $10 \mathrm{~N}$, em ambas as variedades. A firmeza da região placentária foi inicialmente maior em 'Pedro Sato' $(15 \mathrm{~N})$ que em 'Kumagai' $(7 \mathrm{~N})$; no entanto, ao final do armazenamento, ambas atingiram valores próximos a $2 \mathrm{~N}$. De modo geral, as goiabas cortadas em fatias perderam firmeza mais rapidamente que as cortadas em rodelas (Figura 1). Isto ocorre, pois tecidos vegetais lesionados apresentam aumento da produção de etileno, o qual acelera a deterioração e a senescência, promovendo modificações na textura, como observado por Watada et al. (1990) em melancias, kiwis e bananas minimamente processadas.

A temperatura exerceu influência sobre a cor da casca e da região placentária, para ambas as variedades (Figura 2). Houve redução do ângulo de cor $\left({ }^{\circ} h\right)$ durante o armazenamento, ou seja, ocorreu o amarelecimento da casca. Esta mudança foi observada apenas nas goiabas armazenadas a $15^{\circ} \mathrm{C}$. Da mesma forma, houve redução nos valores de luminosidade, para as goiabas a $15^{\circ} \mathrm{C}$, indicando o escurecimento da polpa nesta região. Esta variável diferencia cores claras de escuras e tem sido usada em trabalhos de processamento mínimo para medir o escurecimento do produto ao longo do armazenamento (Arruda et al., 2003b).

O escurecimento da polpa, na região placentária, também foi favorecido pelo corte em fatias (Figura 3). Essa influência é mais evidente na variedade Pedro Sato que na 'Kumagai'. Provavelmente, isso se deve ao fato de goiabas 'Pedro Sato' apresentarem valores médios de luminosidade menores que os da 'Kumagai', mostrando maior suscetibilidade ao escurecimento. Por outro lado, o tipo de corte não influenciou na coloração da casca. Desta forma, a cor na região placentária pode ser utilizada como indicativo da perda de qualidade, pois, à medida que um produto apresenta alterações de suas características originais, seja escurecendo, seja adquirindo outra tonalidade, há o comprometimento da sua aparência e, por conseguinte, da sua aceitabilidade pelo mercado consumidor (Chitarra, 1994). 
O maior escurecimento nas goiabas cortadas em fatias pode indicar que, nestas, a lesão foi maior que naquelas cortadas em rodelas. Provavelmente, o corte em fatias ocasionou maior rompimento de células e, consequentemente, injúria mais intensa. A injúria provoca o rompimento das células, o extravasamento do líquido celular e sua consequente exposição à ação enzimática, o que promove a oxidação de compostos fenólicos a quinonas, levando ao aparecimento de pigmentos de coloração marrom (Radi et al., 1997).

O teor de ácido ascórbico (AA) do produto minimamente processado de goiabas foi influenciado apenas pelo período de armazenamento (Figura 4), não havendo influência da temperatura, ou do tipo de corte. Foram encontrados teores de aproxi-

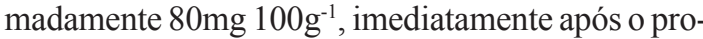
cessamento, os quais aumentaram para até $128 \mathrm{mg}$ $100 \mathrm{~g}^{-1}$, com posterior redução. Jacomino et al. (2001), trabalhando com goiabas brancas 'Kumagai' armazenadas a $10^{\circ} \mathrm{C}$, também observaram aumento neste teor durante o amadurecimento. Os resultados encontrados neste trabalho representam a média das duas variedades, uma vez que foram analisadas as misturas entre as duas cultivares. Desta forma, o aumento no teor de AA deve-se, provavelmente, à variedade Kumagai. A redução observada ao longo do armazenamento é, provavelmente, um indício de senescência. Segundo Mercado-Silva et al. (1998), este aumento no teor de AA em goiabas, durante o início do amadurecimento, está associado ao aumento da síntese de intermediários metabólicos, os quais são precursores do AA, com a degradação de polissacarídeos da parede celular que, possivelmente, resultam em aumento da galactose, que é um dos precursores da biossíntese do AA (Wheeler et al., 1998). Com o amadurecimento, ocorre a oxidação dos ácidos com consequente redução do teor de AA, indicando a senescência do fruto (Tucker, 1993). Mattiuz et al. (2003) verificaram diminuição no conteúdo de AA em goiabas 'Paluma' e 'Pedro Sato' minimamente processadas. Segundo esses autores, os sistemas protetores antioxidantes associados ao AA podem ter sido danificados pelas injúrias mecânicas durante o processamento, permitindo a depleção oxidativa do ácido ascórbico a ácido 2,3 dioxi L-gulônico.

Os teores de sólidos solúveis mantiveramse estáveis durante o armazenamento, não sendo influenciados pelos tratamentos, com exceção do corte em fatia que apresentou ligeiro decréscimo, no $9^{\circ}$ dia de armazenamento. Mattiuz et al. (2003) também observaram manutenção do conteúdo de SS ao longo do armazenamento em goiabas 'Paluma' $\mathrm{e}$
'Pedro Sato'.Segundo Lamikanra et al. (2000), esta estabilidade provavelmente está associada às baixas temperaturas. Estes autores também observaram estabilidade nos teores de sólidos solúveis e de $\mathrm{pH}$ em melões Cantaloupe minimamente processados e armazenados a $4^{\circ} \mathrm{C}$, por 14 dias.

A acidez titulável também não foi influenciada pelos tratamentos e tampouco pelo período de armazenamento. $\mathrm{O}$ menor valor obtido foi $0,6 \%$ de ácido cítrico, e o maior foi 0,8\%. Mattiuz et al. (2003) observaram comportamento semelhante em goiabas 'Paluma' e 'Pedro Sato'. Lima \& Durigan (2000), trabalhando com goiabas 'Pedro Sato', e Jacomino et al. (2002), com goiabas 'Kumagai', observaram leve aumento na AT durante o armazenamento a $10^{\circ} \mathrm{C}$. Os ácidos orgânicos representam um dos principais substratos para os processos respiratórios durante o amadurecimento e de forma geral tendem a diminuir significativamente durante esta fase (Tucker, 1993). O estresse ocasionado pelo processamento mínimo aumenta a atividade respiratória e pode ter desencadeado o incremento da produção de ácidos, via ciclo de Krebs, no início do armazenamento, sendo consumido a seguir como substrato respiratório.

Houve declínio das notas atribuídas à aparência durante o armazenamento refrigerado, sendo que as piores notas foram atribuídas aos produtos mantidos a $15^{\circ} \mathrm{C}$ (Figura 5). Neste tratamento, observou-se perda de frescor, amolecimento e escurecimento da polpa na região placentária e desenvolvimento de colônias microbianas a partir do $6^{\circ}$ dia, enquanto a temperatura de $5^{\circ} \mathrm{C}$ favoreceu a manutenção da aparência durante o período avaliado. $\mathrm{O}$ produto minimamente processado, em rodelas, apresentou notas superiores, indicando a maior preferência dos provadores.

Os tecidos fatiados, cuja superfície de exposição é maior, apresentam maiores taxas de respiração e, consequentemente, maiores alterações fisiológicas, bioquímicas e microbiológicas que o tecido inteiro (Porte \& Maia, 2001; Brecht, 1995). Assim, é de se esperar que diferentes tipos de corte promovam diferentes respostas quanto à qualidade e capacidade de conservação dos produtos minimamente processados (Arruda et al, 2003a).

Todos os tratamentos apresentaram ressecamento, esbranquiçamento do mesocarpo e perda do frescor ao longo do armazenamento. O tecido esbranquiçado, que se forma na superfície de cenoura minimamente processada, denominada "white blush" por alguns pesquisadores, torna o produto com aparência envelhecida e não atraente. Alguns grupos de pesquisadores atribuem este esbranquiçamento à desidratação das células superficiais, devido aos danos causados pelo processamento (Avena-Bustillos et al., 
1994), enquanto outros acreditam que isto ocorre devido à formação de lignina na superfície dos cortes (Bolin \& Huxsoll, 1991). Para um terceiro grupo, o esbranquiçamento é causado pela combinação dos dois processos (Cisneros-Zevallos et al., 1995). A desidratação reflete-se em uma mudança de cor reversível que é tanto mais acentuada quanto maior a perda de água, enquanto a ativação de metabolismo fenólico e a produção de lignina resultam em uma mudança de cor irreversível (Izumi et al., 1996).
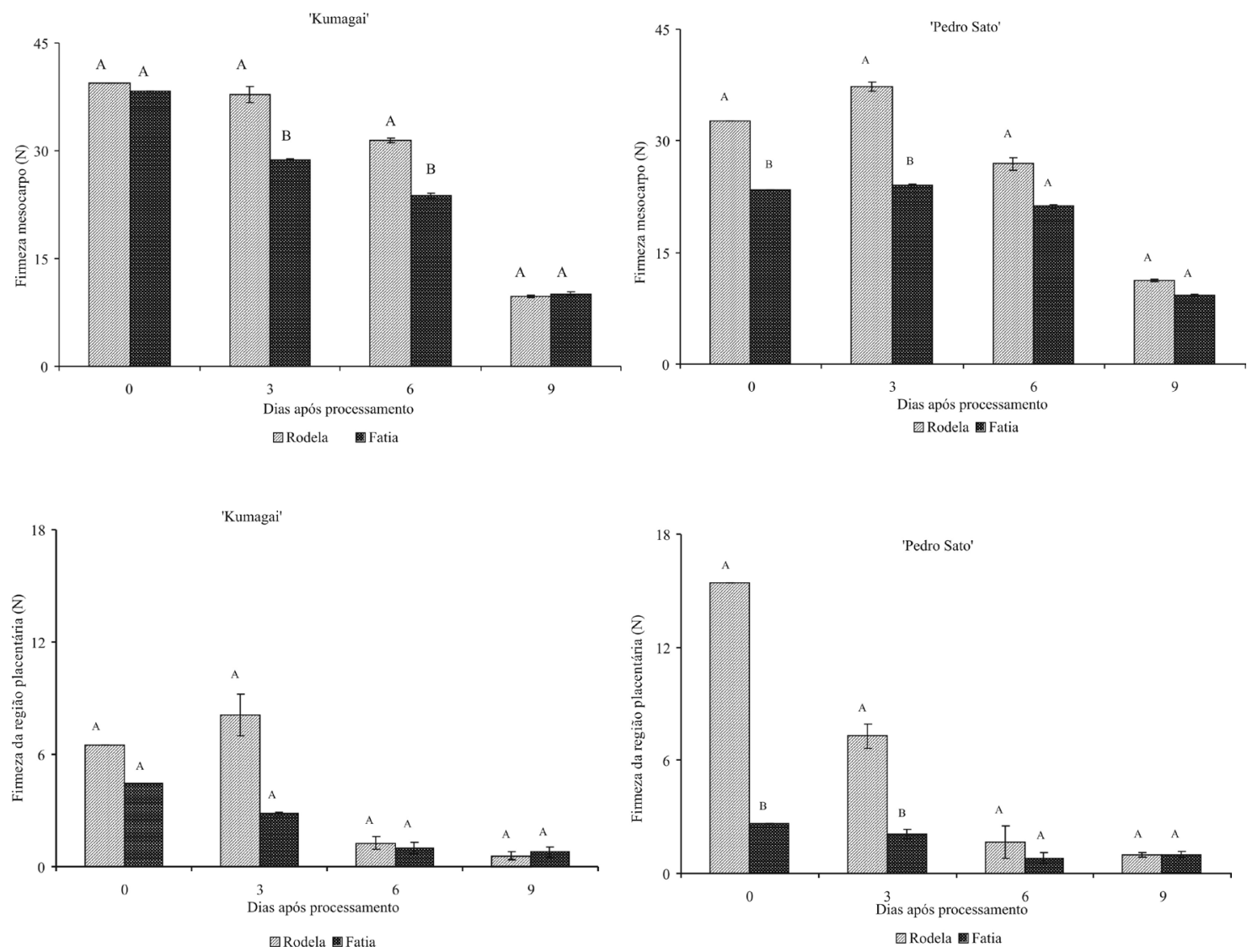

FIGURA 1 - Firmeza do mesocarpo e da região placentária de goiabas minimamente processadas em rodelas e fatias. As barras verticais representam o erro-padrão. Colunas seguidas de mesma letra não diferem entre si, pelo teste de Tukey, a 5\%, em cada dia de análise. 

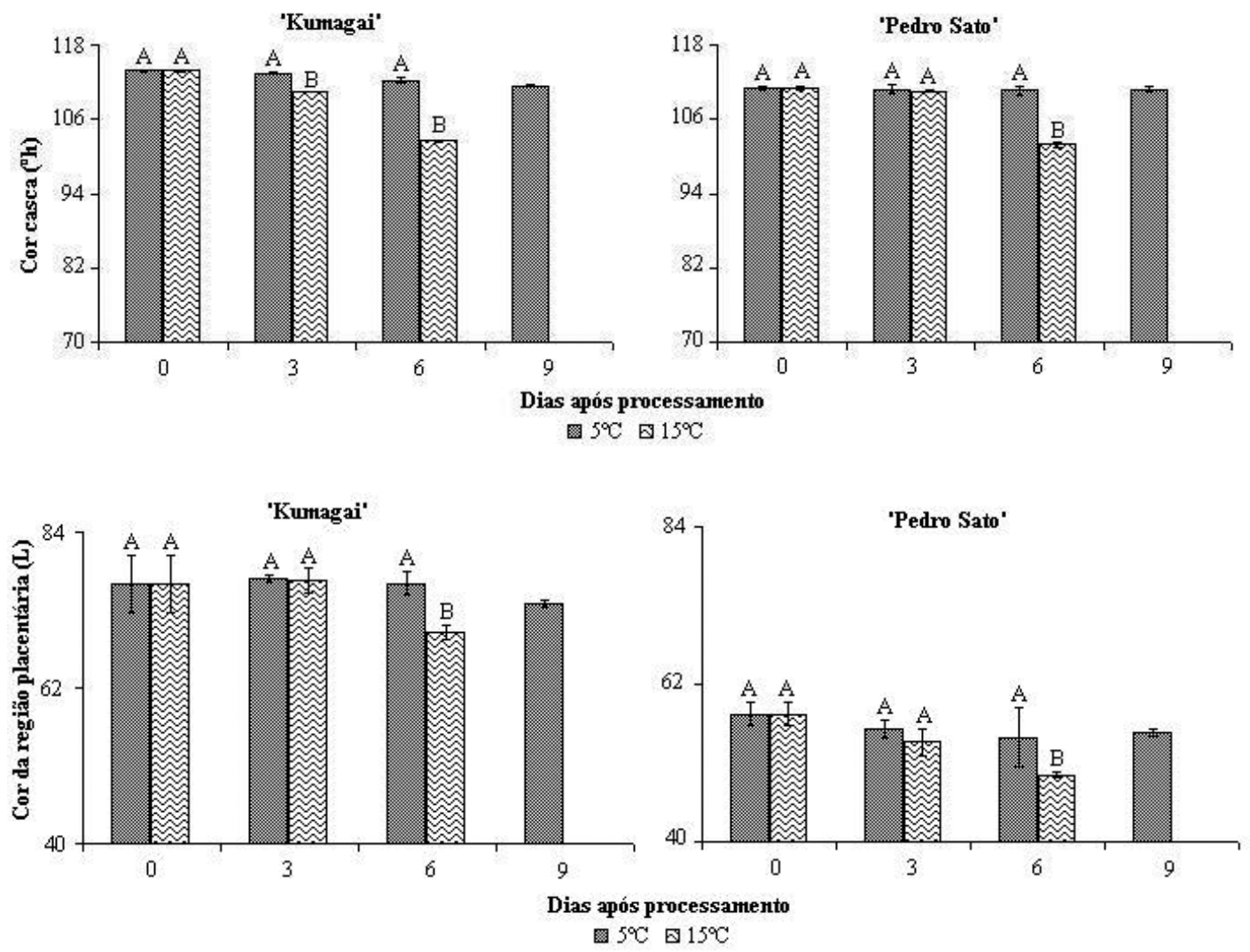

FIGURA 2 - Cor da casca (ângulo de cor) e da região placentária (luminosidade) de goiabas minimamente processadas armazenadas a $5^{\circ} \mathrm{C}$ e $15^{\circ} \mathrm{C}$. As barras verticais representam o erro-padrão. Colunas seguidas de mesma letra não diferem entre si, pelo teste de Tukey, a 5\%, em cada dia de análise.

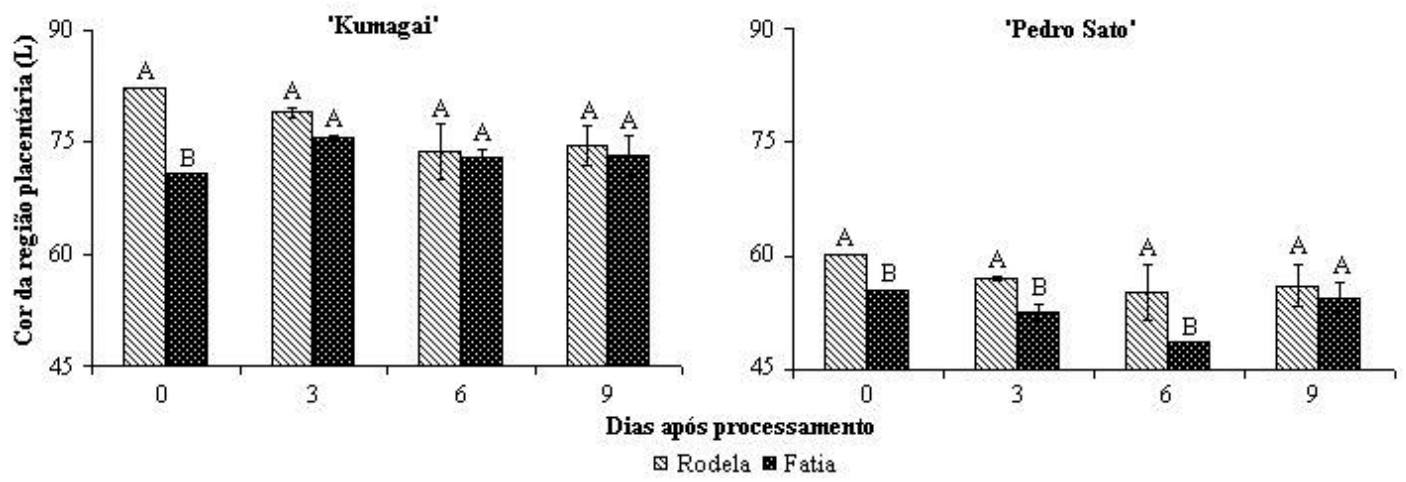

FIGURA 3 - Cor da região placentária (luminosidade) de goiabas minimamente processadas em fatias e rodelas. As barras verticais representam o erro-padrão. Colunas seguidas de mesma letra não diferem entre si, pelo teste de Tukey, a 5\%, em cada dia de análise. 


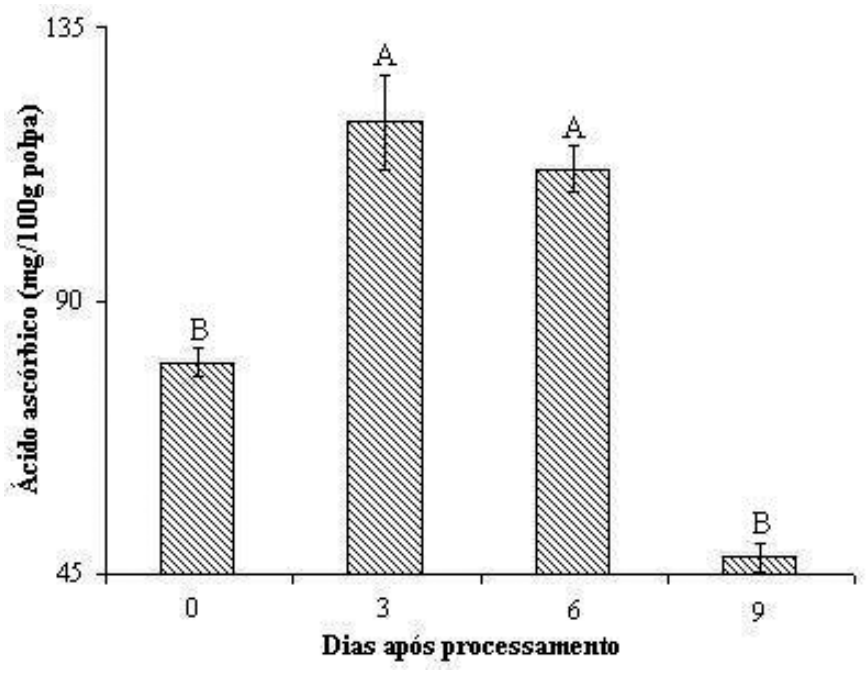

FIGURA 4 - Teor de ácido ascórbico em produto misto de goiabas 'Kumagai' e 'Pedro Sato' minimamente processadas em rodelas e fatias e armazenado a $5^{\circ} \mathrm{C}$ e $15^{\circ} \mathrm{C}$, durante 9 dias. As barras verticais representam o erro-padrão. Colunas seguidas de mesma letra não diferem entre si, pelo teste de Tukey, a 5\%, em cada dia de análise.

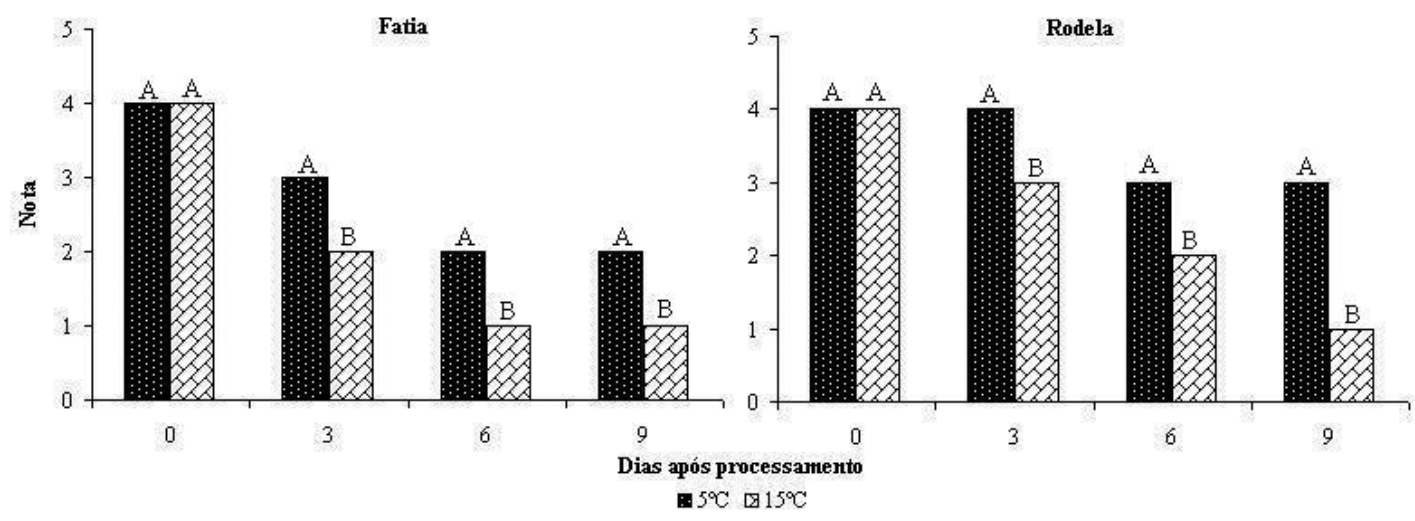

FIGURA 5 - Aparência de produto misto de goiabas 'Kumagai' e 'Pedro Sato' minimamente processadas e armazenado a $5^{\circ} \mathrm{C}$ e $15^{\circ} \mathrm{C}$. Notas: $5=$ ótimo; $4=$ bom; $3=$ regular; $2=$ ruim, e $1=$ péssimo. As barras verticais representam o erro-padrão. Colunas seguidas de mesma letra não diferem entre si, pelo teste de Tukey, a 5\%, em cada dia de análise. 


\section{CONCLUSÕES}

1-O tipo de corte e a temperatura não exerceram influência nos teores de ácido ascórbico, sólidos solúveis e acidez titulável.

2-Temperatura de $5^{\circ} \mathrm{C}$ garantiu manutenção da cor da casca e da aparência e ainda proporcionou maior vida útil ao produto minimamente processado.

3-O corte em rodelas levou a maior manutenção da firmeza da casca e da região placentária, proporcionou menor escurecimento aos frutos e foi o preferido pelos provadores.

\section{REFERÊNCIAS}

ALLONG, R.; WICKHAM, L.D.; MOHAMMED, $M$. The effect of cultivar, fruit ripeness, storage temperature and duration on quality of fresh-cut mango. Acta Horticulturae, Wageningen, n.509, p.487-494, 2000.

AOAC. Official methods of analysis of the Association of Official Analytical Chemists. 12 ed. Washington, 1997. 1115p.

ARRUDA, M.C.; JACOMINO, A.P.; KLUGE, R.A.; AZZOLINI, M. Temperatura de armazenamento e tipo de corte para melão minimamente processado. Revista Brasileira de Fruticultura, Jaboticabal, v.25, n.1, p.74-76, 2003a.

ARRUDA, M. C. de; JACOMINO, A. P.; SARANTÓPOULOS, C. I.G.L.; MORETTI, C.L. Qualidade de melão minimamente processado armazenado em atmosfera modificada passiva. Horticultura Brasileira, Brasília, v.21, n.4, p.655-659, 2003 b.

AZZOLINI, M.; JACOMINO, A. P.; SPOTO, M. H. F. Estádios de maturação e qualidade pós-colheita de goiabas 'Pedro Sato'. Revista Brasileira de Fruticultura, Jaboticabal, v.26, n.1, p.29-31, 2004.

AVENA-BUSTILLOS, R.J.; CISNEROS-ZEVALLOS, L.A.; KROCHTA, J.M.; SALTVEIT, M.E. Application of casein-lipid edible film emulsions to reduce white bush on minimally processed carrots. Postharvest Biology and Technology, Amsterdam, v.4, n.4, p.319-329, 1994.
BOLIN, H.R.; HUXSOLL, C.C. Control of minimally processed carrot (Dacus carota) surface discoloration caused by abrasion peeling. Journal of Food Science, Chicago, v.56, n.2, p.416-418, 1991.

BRECHT, J.K. Physiology of lightly processed fruits and vegetables. HortScience, Alexandria, v.30, p.18-21, 1995.

CAVALINI, F.C. Índices de maturação, ponto de colheita e padrão respiratório de goiabas 'Kumagai' e 'Paluma'. 2004. 69 f. Dissertação (Mestrado em Ciências) - Escola Superior de Agricultura "Luiz de Queiroz”, Universidade de São Paulo, Piracicaba, 2004.

CHITARRA, M.I. Colheita e pós-colheita de frutos Informe Agropecuário, Belo Horizonte, v.17, n.179, p.8-18, 1994.

CISNEROS-ZEVALLOS, L.;SALVEIT, M.E.; KROCHTA, J.M. Mechanism of surface white discoloration of peeled carrots during storage. Journal of Food Science, Chicago, v.60, n.2, p.320-323, 1995.

INTERNATIONAL FRESH-CUT PRODUCERS ASSOCIATION. Fresh-cut produce handling guidelines. 3.ed. Newark: Produce Marketing Association, 1999. 39p.

IZUMI, H.; WATADA, A.E.; KO, N.P.; DOUGLAS, W. Controlled atmosphere storage of carrots slices, sticks and shreds. Postharvest Biology and Technology, Amsterdam, v.9, n.2, p.165-172, 1996.

JACOMINO, A.P.; ARRUDA, M.C. de; MOREIRA, R.C.; KLUGE, R.A. Processamento Mínimo de frutas no Brasil. In: SYMPOSIUM ESTADO ACTUAL DEL MERCADOS DE FRUTOS Y VEGETALES CORTADOS EN IBEROAMÉRICA, 2004, "San José" Costa Rica. Resumos... p.79-86.

JACOMINO, A.P.; CAVALINI, F.C.; ARRUDA, M.C.de; PINTO, P.M.; PINHEIRO, A.L.; ATHIÊ, S.M. Goiaba e frutas cítricas: opções para o processamento mínimo. In: LOBO, G.M.; GONZÁLES, M. (Ed.). Procesado mínimo de frutas. Cartagena: Gráficas Sabater, 2007. p. $55-69$. 
JACOMINO, A.P.; KLUGE, R.A.; BRACKMANN, A.; CASTRO, P.R. de C. Amadurecimento e senescência de mamão com 1-metilciclopropeno. Scientia Agricola, Piracicaba, v.59, p.303-308, 2002.

JACOMINO, A. P. ; SIGRIST, J. M. M. ; SARANTÓPOULOS, C. I. G. de L. ; MINAMI, K. ; KLUGE, R. A. Embalagens para conservação refrigerada de goiabas. Revista Brasileira de Fruticultura, Jaboticabal, v. 23, n. 1, p. 50-54, 2001.

LAMIKANRA, O.; CHEN, J.C.; BANKS, D. Biochemical and microbial changes during the storage of minimally processes cantaloupe. Journal of Agricultural and Food Chemistry, Washington, v.48, p.5955-5961, 2000.

LIMA, M.A.; DURIGAN, J.F. Conservação de goiabas 'Pedro Sato' associando-se refrigeração com diferentes embalagens. Revista Brasileira de Fruticultura, Jaboticabal, v.22, p.232-236, 2000.

MATTIUZ, B.; DURIGAN, J. F.; ROSSI JUNIOR, O. D. Processamento mínimo em goiabas 'Paluma' e 'Pedro Sato': 2. Avaliação química, sensorial e microbiológica. Ciência Tecnologia de Alimentos, Campinas, v.23, n.3, p.409-413, 2003.

MERCADO-SILVA, E.; BENITO-BAUTISTA, P.; GARCIA-VELASCO, M. A. Fruit development, harvest index and ripening changes of guavas produced in central Mexico. Postharvest Biology and Technology, Amsterdam, v. 13, p. 143-50, 1998.

PERYAM, D. R.; GIRARDDOT, N. F. Advanced taste method. Food Engineering, Radnor,v.24, p.58-61, 1952.
PORTE, A; MAIA, L.H. Alterações fisiológicas, bioquímicas e microbiológicas de alimentos minimamente processados. Boletim do CEPPA, Curitiba, v.19, p.105-118, 2001.

RADI, M.; MAHROUZ, M.; JAOUAD, A. Phenolic composition, browning susceptibility, and carotenoid content of several apricot cultivars at maturity. HortScience, Alexandria, v. 32, n. 6, p. 1087-1091, 1997.

TUCKER, G. A. Introduction. In: SEYMOUR, G. B.; TAYLOR, J. E.; TUCKER, G. A. (Ed.). Biochemistry of fruit ripening. London: Chapmal \& Hall, 1993. cap. 1, p. 2-51.

VAROQUAUX, P.; WILEY, R.C. Biological and biochemical changes in minimally processed refrigerated fruits and vegetables. In: WILEY, R.C. (Ed.). Minimally processed refrigerated fruits \& vegetables. New York: Chapman \& Hall, 1994. cap.6, p.226-268.

WATADA, A.; ABE, K.; YAMAUCHI, N. Physiological activities of partially processed fruits and vegetables. Food Technology, Chicago, v. 20, p. 116-122, 1990.

WHEELER, G.L.; JONES, M.A.; SMIRNOFF, N. The biosynthetic pathway of vitamin $\mathrm{C}$ in higher plants. Nature, London, v.393, p.365-369, 1998. 